\title{
DEVELOPMENT TRENDS IN AUSTRALIAN SCIENTIFIC RESEARCH
}

\begin{abstract}
$\mathrm{T}$ HE tenth annual report of the Commonwealth of Australia Scientific and Industrial Research Organization covers the year ended. June 30, 1958 (pp. 174. Canberra: Government Printer, 1958. $14 s$.$) , in which the Organization expended £ 6,861,278$ on normal research activities, $£ 429,328$ on capital works and $£ 123,655$ on grants to outside bodies. Of its total income of $£ 7,414,261, \mathfrak{f 5 , 7 9 2 , 8 9 4}$ was from Treasury funds and $£ 1,267,928$ from the Wool Research Trust Fund. Grants to research associations totalled £41,260 and for Overseas Research Student. ships $£ 60,793$. Expenditure on investigations into plant problems amounted to $£ 754,835$; into animal

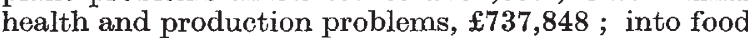
preservation and transport, $£ 245,125$; into forest products, £316,322; into entomology, $£ 215,538$; into fisheries, $£ 171,458$; and into industrial chemistry, $£ 624,169$. $£ 577,186$ was spent on the National Standards Laboratory, $£ 149,098$ on building research, $£ 383,672$ on radiophysies research, $£ 384,823$ on wool textiles research, $£ 175,792$ on fuel research, $£ 119,338$ on the wild-life survey, and $£ 154,929$ on land research and regional survey. A list of staff as well as pub-
\end{abstract} lished papers is included in the report.

A representative committee appointed to consider the future development of the National Standards Laboratory found that while the Laboratory was functioning at a high level of efficiency, the staff and accommodation were too limited and future plans should include a well-planned programme of research. The testing and calibration service for industry also required expansion, and in sequence with a further recommendation, Mr. N. A. Esserman has been appointed as first director of the Laboratory. Further new arrangements with the universities were concluded during the year, including the development of a Biological Inorganic Chemistry Unit in cooperation with the Australian National University, establishment of a joint electron microseopy labor. atory at the University of Sydney, and of a readership in dairy husbandry, also at Sydney. The design study of the proposed giant radiotelescope has been completed and the instrument is to be constructed on a site near Parkes, New South Wales. Some extension of the technical liaison services of the International Wool Secretariat and its affiliated organizations was agreed and the Secretariat and the Australian Wool Bureau are co-operating in making known to clothing manufacturers throughout the world the Organization's Si-ro-set process for the permanent pleating and creasing of garments. The heavy pellet developed in the Division of Biochemistry and Animal Nutrition for administering cobalt supplements to sheep has been widely adopted by graziers in Australia. The work of the Organization's Plant and Soils Laboratory, Brisbane, has already established that the carrying capacity of the area of Queensland south of the Tropic of Capricorn and receiving good rainfall can be greatly increased by replacing natural pastures by sown pastures, and the work is of special interest to the beef cattle industry.

The Division of Soils has developed a new section to meet the increasing demands for study in soil microscopy and its Soil Mechanics Section continued to widen its interests, especially in foundation problems in building, in pavement engineering and in the stabilization of soils. Morphological and chemical data are being compiled for three representative profiles of each of the great soil groups which have been recognized in Australia. It is proposed to base the main research of the Division of Plant Industry on semi-arid native grasslands at Deniliquin, New South Wales, and to use this as a centre for studies of the establishment and maintenance of sown pasture species under dry-land conditions. Studies were continued on the effect of clover on the fertility of the soil and the residual effects of phosphorus, sulphur, boron and molybdenum; on the extraction from Thiobacillus $X$ (Thioparus) of an enzyme and some cytochrome components which catalyse the oxidation of thiosulphate to tetrathionate; and on the effect of individual growth substances on cell division and size of fruits. Experiments continued on the transfer of resistance to blue mould (Peronospora tabacina) from Australian species of Nicotiana to commercial varieties of $N$. tabacum. An extremely dry year was utilized to study the eapacity of sown pastures to carry sheep and to persist under high rates of stocking and under different systems of utilization. Studies of the effects of nitrogen supply and extension of the growing season on four strains of $P$. tuberosa were completed, and an improved electron dialysis technique involving a minimum of damage to the plant tissue has been developed for determining the cation-exchange capacity of plant roots. Studies continued on the beneficial effects of wilting on the ensilage of ryegrass and on the drying characteristies of pasture plants as affected by air velocity, humidity and temperature.

The two irrigation research stations on which the ways in which irrigated land can be made to keep its fertility are being studied, and the techniques which can be used to reclaim waterlogged or salted soil, continued their research programmes without major change, and the Department of Agriculture, New South Wales, is co-operating in the Murrumbidgee areas in studies of control of iron chlorosis and of effects of waterlogging and salting on the nutrition of apricots and peaches. The Division of Animal Health and Production has commenced work on the protozoal blood parasites which cause 'tick-fever' in cattle. Good progress is being made towards an understanding of the physiological characteristics which determine heat tolerance in cattle, with a view of selecting them within the European breeds or importing them, by crossing with such breeds as the Zebu or Afrikander. Diseases of sheep now receiving special attention are foot-rot and foot abscess, mycotic dermatitis and worm parasites. Sheep husbandry and wool production are two of the Division's major research undertakings, with the view of understanding the genetic basis of high wool production, and the nutritional and other physiological mechanisms which enable the inherited capacity for high wool production to be manifested, redueing the heavy losses due to poor fertility and 
neo-natal mortality in lambs, and discovering the best and most economic means of offsetting the effects of drought by appropriate maintenance rations and husbandry. The present status of animal husbandry and production investigations by Commonwealth and State organizations is under review to reveal the nature of the major problems on which attention could most usefully be focused. At the Division of Biochemistry and General Nutrition's field stations experiments are being conducted on salt tolerance and supplementary feeding and on cobalt and copper deficiencies, including trials of the cobalt pellets developed to protect sheep from cobalt deficiency and phaleris staggers.

No major changes are reported in the research programme of the Division of Entomology, and great stress continues to be placed on the ecological approach. An officer has been appointed to study the ecology of the cattle tick in North Queensland, and work on cattle dips and pasture spelling is being intensified. In systematics some progress has been made on a revision of the Calliphoridae or blowflies, and revisions of the Pyrgotidae and Acroceridae have been completed. Preparation for the Commonwealth-State trial in New South Wales of a proposed method of suppressing outbreaks of the Australian plague locust advanced considerably, and in work on insect pests of stored grain the density of insect population is being studied under conditions of controlled oxygen leakage. Relations between chemical structure and insecticidal activity have been examined in the volatile ketones and $\mathrm{N}$-substituted amides of long-chain fatty acids.

The Wildlife Survey Section intensified its study of rabbit populations and has initiated investigations of the dingo (Canis familiaris dingo) and the fox (Vulpes vulpes). Besides land surveys of the underdeveloped regions by the Division of Land Research and Regional Survey to determine their needs and population, the Division of Biochemistry and General Nutrition is investigating problems of plant and animal nutrition on the Coonalpyn Downs, South Australia; the Division of Animal Health and Production is breeding cattle at Belmont, Rockhampton, Queensland; and the Plant and Soil Laboratory is studying the wallum country in eastern Queensland. The Division of Fisheries and Oceanography has built an experimental aquarium at Cronulla to study the behaviour patterns of commercial fish and has devised and tested a method for counting and differentiating phytoplankton at sea. There was no change in emphasis of the work of the Division. The Division of Food Preservation and Transport initiated, jointly with the New South Wales Department of Agriculture, a three-year investigation of levels of fruit spray residues and their removal. The cheese curd fusing machine developed by the Dairy Research Section was put through successful trials and could be the first effective attempt to mechanize cheese manufacture completely. Work on the biophysical properties of the giant cells of Chara australis was resumed, and a study of the properties of sucrose synthesized by enzymes was completed. The co-operative research programmes undertaken by the Division of Building Research steadily increased during the year, including an investigation into the use of ordinary household hot-water heaters, fired by brown coal briquettes for space heating as woll as water-heating to lower-and medium-priced houses.
The Wool Textile Research Laboratory has developed an improved sampling device for wool and devoted greater effort to shrink-proofing, including the use of oxidizing agents. Studies continued on the exchange of water between a mass of wool and the air passing through it, and work in the Division of Industrial Chemistry on the structural analysis of amino-acids has been extended to the peptides. A major activity of the latter Division has been in the techniques of extractive metallurgy and a full-scale unit is to be installed for final tests on the recovery of uranium from Dyson's ore by the Weiss-Swinton jigged bed process for continuous ion exchange. Also in co-operation with industry the Division has completed an investigation of the fluid bed roasting of copper concentrates and the subsequent locating and electromining of copper. A process has been developed for obtaining thorium of high purity, and further kinetic studies were made on the decomposition of sulphide minerals in the presence of water and oxygen. The investigation of the constituents of tar from Lurgi gasification plant continued, as well as the study of the production and properties of various kinds of defects in crystals and their bearing on chemical and physical properties of solids, while increasing effort was devoted to the design and development of optical and spectroscopic equipment. An investigation on the preparation of substituted sebacic acids of possible value as plasticizers and low-temperature lubricants showed that the isomeric dihydroxysteric acid easily prepared from oleic acid, as well as erythro-dihydroxysteric acid can be converted to $\alpha$-hydroxy- $\alpha$-octylsebacic acid by alkali fusion and in considerably higher yields. The Coal-Research Section is continuing work on the properties, composition and structure of light oils, tars and pitches produced by the carbonization of Australian coals.

The Division of Tribophysics continued its fundamental studies in metal physics, surface physics and the chemistry of solids, and in some co-operative work on the refining of lead the surface properties of liquid lead have been measured in various media by a radiographic technique. No new major projects were initiated in the Division of Physics, where the accuracy of the Laboratory's realization of the International Temperature Scale at high temperatures has been considerably increased, and proposals have been formulated for its extension to well below the present lower limit of $-183^{\circ} \mathrm{C}$, based on an investigation of the dependence on temperature of the electrical resistance of platinum. Electronic apparatus designed or constructed in. cludes a photoelectric servo system for the control of a physical balance for measuring strong magnetie fields; a nuclear resonance thermometer using the quadrupole resonance of chlorine ; and the control to 1 in 10 of currents up to $10 \mathrm{amp}$. in an electromagnet with a galvanometer amplifier and power transistors. No major changes are reported in the work of the Division of Electrotechnology, but its high-voltage measuring facilities are to be expanded. Special furnaces have been constructed and preliminary experiments made to determine the conditions of crystal growth most likely to yield satisfactory single organic crystals, while further studies have been made on the dielectric properties of polycrystalline materials and liquids. Determinations of the frequency factors and energies of activation of methyl ethers and ketones confirmed that in long-chain compounds the logarithm of the frequency varies linearly with the energy of activation. 
The continuance of the investigations of the Division of Radiophysics into the practicability of increasing rainfall by seeding clouds with silver iodide by a further large-scale field trial is in progress in the Northern Tablelands region of New South Wales. Development continued of a method for obtaining bearings from existing Distance Measuring Equipment Beams and also research into the purification of semiconductor materials and growth of mono crystals, the transport of charges in semiconductors and the development of junction photo devices. An all-sky camera was installed in October 1957 and photographs of the whole night sky have been taken regularly at five-minute intervals since that time, recording any auroræ that may occur, and in conjunction with cameras at other stations, enabling positions and height of auroræ to be deduced. In solar physics the association between a class of radio bursts conventionally known as type II and optical features in the chromosphere has been investigated, while the main observational programme of the 15-metre wave-length "Cross" aerial was directed towards completing a survey of a belt of the sky, $10^{\circ}$ wide, around the galactic equator. The crossed-grating interferometer is producing each day a detailed radio picture of the Sun, and observations of solar radio disturbances continued throughout the year with the Dapto radio spectrograph, which records the Sun's spectrum in the range of wavelengths between about 1.5 and $7.5 \mathrm{~m}$. The Mathematical Instruments Section completed the construction of the transistorized digital differential analyser and the techniques are being applied to the development of a small general-purpose computer.

\section{DELAYED HYPERSENSITIVITY IN IMMUNOLOGY}

T HE mechanism of the delayed form of hypersensitivity, originally and still exemplified by Koch's tuberculin reaction, has proved much more difficult of analysis than that of the immediate reaction about the main immunological features of which much is now known. In the symposium on "Delayed Hypersensitivity" held by the British Society for Immunology in London on May 8, the allergic phenomena associated with reactions of this type provided the central theme for discussion.

Little progress towards the understanding of the mechanism of the tuberculin reaction can be expected, as pointed out by $\mathrm{S}$. V. Boyden in opening the Symposium, until the nature of the specific change in the tissues responsible for the hypersensitivity is recognized and can be detected and measured in vitro. The injection of tuberculoproteins, when in soluble form, leads to the production of specific antibodies in the blood but not to the appearance of delayed hypersensitivity. Even when these proteins are adsorked on carbon granules or red cell stromata to provide them with a particulate vehicle, their injection almost invariably results in the development of Arthus-type hypersensitivity. It seems that it is only when these antigens enter the tissues as an integral part of the bacillus, and consequently pass through some intracellular experience in phagocytes, that the animal will respond to a subsequent skin test with a typical delayed tuberculin reaction.

In part, the characteristic delay in the development of the tuberculin reaction might be attributable, as $d$. Pepys has observed, to the period of several hours needed for the full fixation of the provocative agent to the tissue cells. The simultaneous injection of any agent, such as histamine or hyaluronidase which can accelerate the loss of the tuberculin from the site of inoculation, or of adrenalin which can ensure its retention in the area, consequently much affects the intensity of the ensuing reaction. It follows, therefore, that any constituent present in the tuberculin preparation used that might evoke even a relatively inconspicuous immediate reaction could, by so doing, lead to the dispersal of the factor which was the cause of the delayed reaction and so mask any later manifestations of delayed hypersensitivity. On the other hand, the introduction of the tubereulin in a lipid vehicle prolongs the local retention of the tuberculin, thereby enhancing its potency and revealing in man the presence of degrees of hypersensitivity too low to be demonstrable by intracutaneous tests with large doses of tuberculin.

The discovery by Landsteiner and Chase that in guinea pigs specific delayed hypersensitivity can be transferred by an inoculum of leucocytes when one of serum is ineffective has been further analysed for human beings by H. S. Lawrence. He sought, by making extracts from such cells after their lysis, to identify the 'transfer factor' concerned. This he found to be a stable agent capable of resisting exposure to deoxyribonuclease, ribonuclease and trypsin. With Pappenheimer, he found that it may be liberated from the sensitizing leucocytes by incubation alone or by contact with tuberculoproteins; the latter procedure caused the cells themselves to lose their distinctive property of sensitizing a recipient. Delayed hypersensitivity to coccidioidin is similarly transferable with extracts of sensitizing leucocytes and the specific systemic reactivity so conferred may persist for more than a year.

In seeking some biological meaning for delayed hypersensitivity reactions, Lawrence proposed an extension of Burnet and Fenner's 'self-marker' concept to postulate that interaction between host cells and phagocytozed microbes may produce slightly altered versions of the individual's cellular components by forming intimate (self plux $x$ ) complexes. The latter, recognized as foreign by the host, may provoke a cellular immune response (transfer factor) directed against the complex. The cellular immune response takes effect against the host's own tissues in the form of a local homograft reaction wherever and whenever his cells are in appropriate combination with the antigen $(x)$ which has induced the alteration. The effector mechanism (transfer factor) is uncovered following transfer to recipients and in the presence of the test antigen $(x)$ it is postulated that it evokes a train of events similar to that called forth by the intact microbe in the cells of the donor.

N. A. Mitchison further followed up the possible resemblances between delayed hypersensitivity and the homograft reaction by pointing out that in both, the immunological responses appeared to be attributable to the participation of cell-bound antibody. A graft of tissue from one animal to another of the 